\title{
Distraction and digital media
}

\section{Multiplexing, not multitasking in the classroom}

Jesper Tække, Aarhus University

Michael Paulsen, University of Southern Denmark

\section{Abstract}

Research shows that when we multitask, we spend more time, remember less, learn less and perform worse than if we singletask. The article "Mobile Phones in the Classroom" (Kuznekoff et al. 2015) is worth highlighting in this connection, as it is one of the most frequently cited articles on multitasking. It shows how damaging written interaction through social media is for learning in teaching situations. But does this mean that social media and written interaction should not be used in teaching? And that social media and written interaction can only harm learning? In this article we provide a critical review of Kuznekoff et al. (2015). We argue that their laboratory experiment is taken out of real educational context, and that this leads to false conclusions. With a background in medium theory and media didactics, we analyse this experiment and point out its shortcomings. Based on a qualitative real-life action research project, we demonstrate that it is possible to develop conditions that make written interaction through social media beneficial to education. Furthermore, we remove the lack of clarity in this area by distinguishing between diffused concentration (multitasking), non-diffused concentration (singletasking) on one axis, and the use of only one medium (singleplexing) and several media (multiplexing) on another orthogonal axis. The upshot is that the use of social media and written interaction in teaching might have educational value, especially when it takes the form of singletasking combined with multiplexing. Kuznekoff et al. overlook this possibility. 


\section{Introduction}

Research extending at least a hundred years back in time shows that we cannot multitask, or that multitasking is a bad strategy in relation to work and learning efficiency (Pashler, 1994; König, 2005; O'Brien, 2011; Wood et al. 2012; Lee et al. 2012; Kuznekoff et al. 2015). In this article we do not try to rebut this research, but seek to add further perspectives to the debate in relation to teaching and learning by introducing the concept of multiplexing, which means focusing your attention on the same object using more than one medium (but not on different objects at the same time, as in multitasking). The public debate regarding the mass media claims that the problems involved in multitasking can be solved by turning off all digital media because of the distraction and even compulsive abuse and addiction to which the use of such media may lead (Kardaras, 2016; Prehn \& Rashid, 2017). As far as we know, there is no scientific evidence for this view, which is not the same as saying that there are no problems in relation to the contemporary digital medium revolution (Finkelhor, 2011; Aagard, 2018). The research that has been done on this topic indicates that the problems are related more to social, educational and cultural issues than to anything else (Hougaard, 2018; Elf et al. 2015; Tække \& Paulsen, 2016). And abuse research (Greenfield, 1999; 2000; Young, 1999; 2006; Chou, 2005) indicates that addiction and abuse problems are pathologies affecting only about $4 \%$ of the population. According to Paulsen \& Tække (2010), up to 70\% of all students feel distracted by digital media in the classroom; and according to Mathiasen (2014), at least half of all students have the same feeling. So the distraction problem is considerable and should primarily be interpreted as a secondary effect of the lack of normative regulation of the new digital teaching environment. Following Meyrowitz (1986), the analogue electronic medium revolution (and the previous medium revolutions) meant that the norms developed in the previous medium environment did not cover the new information situations created by the new medium environment. As a result, at least some of the problems in relation to digital media should be seen as ambivalences related to being in a new information and communication situation (Tække \& Paulsen, 2013; 2010). The way to develop adequate norms and didactics in the new medium environment is not to prevent access to all digital media, but to use new media and do experiments. This does not imply that all teachers and students have to use all kinds of digital media all the time - that would be both impossible and undesirable. What we are arguing here is only two things. First of all, that adequate norms and digital literacy cannot be developed if a general prohibition of digital media use is introduced in all educational contexts. Secondly, that decisions regarding who should use what media when should primarily be decided not outside the world of education, but within teaching in the interaction between teachers and students - because only on this interactional level is it possible to make educationally relevant choices and develop norms and literacy from below. If digital media are totally forbidden in schools, students will get no real help from their teachers to develop insight into the difference between good and bad media use.

Empirically we will back up our argument by presenting knowledge about teaching and written interaction from the Socio Media Education action research project (Tække \& Paulsen, 2013; 2016; 2017). This will support the claim that written interaction has a potential in education, and that in certain circumstances it can strengthen concentration, understanding, interpretation, note writing, retrieving, organisation, emancipation and social relations (also between the teacher and the students). This conclusion is contrary to the prevailing understanding of social media, written interaction and education, as presented by the widely cited article and research of Kuznekoff et al. (2015). There are two main differences. Firstly, Kuznekoff et al. do not distinguish carefully between multitasking and multiplexing. Only multitasking is emphasised, and the potential of multiplexing is therefore not realised. Secondly, Kuznekoff et al. do not cover real educational situations and therefore overlook possibilities that can only be utilised after teachers and students develop new ways of dealing with digital media. The aim of this article is thus two-fold: on the one hand and firstly, we present our critical assessment of Kuznekoff; on the other hand, and secondly, we demonstrate and exemplify how teachers and students can develop teaching into a situation in which social media and written interaction can have educational value. 


\section{The structure of the article}

Our argument is structured as follows: first, we present and discuss research on multitasking in relation to education. This includes an explanation of the differences between singletasking and multitasking, and between multitasking and multiplexing. We argue that these differences must be taken into account in order to understand the new media situation adequately. Secondly, we present and discuss in detail the results achieved by Kuznekoff et al. (2015). We show that these results are based on an inadequate understanding of multitasking, media and education, and that they are misleading because they give the impression that social media and written interaction can have no positive educational value. These two sections form the first part of our argumentation. In similar ways, the second part of the article also consists of two sections: one more general in nature, and one more empirical. While the two sections of the first part are mainly critical, the two sections of the last part are mainly constructive. Thus, in the second part, section one, we turn to our own research, providing a short introduction to the present situation facing education with regard to the digital medium revolution. We do this by introducing our theory of three waves (Tække \& Paulsen, 2017). This theory provides a better framework for understanding the new media situation in relation to education. In part two, section two, we present examples from the SME experiment to discuss in detail multiplexing in relation to singletasking and multitasking in real educational situations. This enables us to demonstrate that it is possible to develop conditions in which social media and written interaction in teaching can produce educational value. Finally, we end the article by summing up and presenting our conclusions about multiplexing, singletasking and multitasking.

\section{Part I: Critical assessment of the prevailing understanding of multitasking and education}

\section{Multitasking}

Research on multitasking clearly seems to reject the use of multitasking in learning situations. If students do multitask, the research shows that the tasks in question will be performed more poorly and take longer time, with students learning less and remembering less about what they have done than is the case when tasks are performed one at a time (Pashler, 1994; König, 2005; O’Brien, 2011; Rekart, 2012; Lee et al. 2012). One mitigating factor is that young students to some extent learn to cope with media activities occurring at the same time as teaching (Bardhi et al. 2010). After all, multitasking is not a pathology (Aagard, 2018).

For more than 100 years, psychologists have been interested in the (in)ability to perform two or more activities at the same time (Pashler, 1994). In general, research shows that our attention is disturbed if we try to do several things at the same time (Pashler, 1994). However, "attention" is a term that covers several sub-areas of consciousness, perception, memory functions, etc., implying metaphysical/philosophical discussions and ambiguities (Pashler, 1994).

However, others (for example, König, 2005) do not define multitasking as performing different activities simultaneously, but as the ability to achieve multiple action goals within the same time period, by switching between individual activities in order to achieve certain goals. In this definition, multitasking is perceived as the ability to switch rapidly between different activities - rather than being able to perform these activities strictly simultaneously.

It can be concluded that students may not be able to multitask effectively in the strict definition of the word, but that they can learn to switch more effectively between different activities. In a study of 132 
undergraduate students, König (2005) shows that it is not possible to multitask effectively, in the sense of simultaneously performing several tasks at the same time, but that we do have the ability to switch between different activities, depending on how good our short-term memory or working memory is. However, this individual ability is not only something that can be learned - it can also be unlearned. For instance, older people are typically less able to switch between different activities that require decisions, actions and reflection than young people. But no matter how good your working memory is, it seems to be weakened by multitasking (in the strict sense of performing different tasks simultaneously) (O'Brien, 2011). One test of 130 students shows that we absorb less information when we do more than one thing at a time (for instance watching a video and reading, then answering questions) (Lee et al. 2012).

Finally, brain research shows that if we do two things at once, the sum of our brain activity is less than the total amount of activity when the same two things are done separately and sequentially (given the same total time interval). This means that it is quicker to perform two tasks (that do not matter to each other) separately than to try and perform them at the same time. Multitasking reduces brain activity and results in reduced learning and problem solving. Not only short-term learning but also long-term learning are likely to be damaged by multitasking; and people who multitask frequently are more easily distracted than people who rarely multitask (Rekart, 2012).

However, according to Aagard (2018) such experiments (like the one by Lee et al. 2012 and König, 2005) only cover situations in which students attend teaching and simultaneously are asked to perform tasks which have nothing to do with the teaching. Such studies only deal with cases involving the use of digital media exclusively and explicitly to distract the students, and the result is hardly surprising: students cannot concentrate fully when they are distracted. We will return to this point in the next section.

The counter concept to multitasking is singletasking. Singletasking does not imply that people are thinking of only one thing for a certain period of time. Logically, if a person reflects on a topic, the topic involves (most often if not always) several objects, concepts and causalities. As a result, creative thinking implies a kind of multiperspectivism but is still a kind of thinking in which topics and concepts from completely irrelevant fields do not intervene. Using a Husserlian term, the intentional object is given in a horizon that enlightens it as a meaningful context (Pietersma, 2000). One borderline case could be what Pierce calls abduction, defined as a situation in which a concept from another domain enlightens our thinking like a metaphor (Jørgensen, 1993). In our definition of singletasking, abduction involves singletasking if this technique of reasoning is used to inform and understand only one single intentional learning object. Another borderline case is group work, in which a polyphony of different meanings meet each other in discussions. Again, we draw a distinction by saying that if a class or group only discusses one single object, e.g. how to understand $\mathrm{X}$, we refer to this as singletasking. If some people in the group begin to discuss other objects ( $\mathrm{Y}, \mathrm{Z}$ etc.) in an unrelated way, we refer to this as multitasking.

Now the question is if singletasking in this definition is possible and perhaps more useful and better suited to the present medium environment. This is a very old discussion because Plato made it clear a very long time ago that writing harms our memory. What Plato could not know is that history has shown that because of writing arguments have grown longer and more consistent, and our vocabulary has grown much bigger (Ong, 1982). The start of printing meant that this process continued and new developments took off like the invention of the index and the possibility of comparing arguments (Eisenstein, 1983). Even so, Plato is still right in one sense because our ability to remember things by heart has declined as we have learnt to write things down, look things up in an encyclopedia etc. On the other hand, this also means that humans began to use more than one medium at the same time when performing activities like studying, thinking, communicating, reflecting, learning etc. This combined use of several media with different and supplementing intellectual affordances provided a new version of homo sapiens with much larger cognitive capacities. Inspired by Fahey \& Meaney (2011), we call this phenomenon multiplexing. We define multiplexing as focusing our attention on the same intentional object using more than one medium. ${ }^{i}$ Even in the pre-internet school system, many different multiplex 
strategies had been developed. For instance, teachers said things aloud as they wrote them on the blackboard; while students listened, looked at the blackboard and wrote things down in their notebooks.

After these general clarifications, we now turn our attention to the frequently cited article by Kuznekoff et al. (2015), presenting a summary and then a critical discussion of this article.

\section{Effects of intentional distraction of students}

The article: "Mobile Phones in the Classroom: Examining the Effects of Texting, Twitter, and Message Content on Student Learning" (Kuznekoff et al. 2015) is worth highlighting as it is one of the most frequently cited articles on multitasking. The article depicts an experiment involving eight groups of students and a control group who watched a film, took notes and were tested to see how much they had learned. The control group had to hide their mobiles away and only take notes by hand.

1. A group exposed to a message relevant to the teaching every $60 \mathrm{~s}$.

2. A group exposed to a message relevant to the teaching every $30 \mathrm{~s}$.

3. A group that was instructed to compose tweets related to the film every $60 \mathrm{~s}$.

4. A similar group, whose participants had to compose tweets every $30 \mathrm{~s}$.

5. A group exposed to a message not relevant to the film every $60 \mathrm{~s}$.

6. A group exposed to a message not relevant to the film every $30 \mathrm{~s}$.

7. A group that was instructed to compose tweets that were irrelevant to the film every $60 \mathrm{~s}$

8. A similar group, whose participants had to compose tweets every $30 \mathrm{~s}$.

The researchers' hypothesis, which was proven, was that the students would be distributed in linear fashion in this order, with the control group achieving the best level of learning and group 8 the worst. At first glance this experiment makes probable that students perform best if they do not use interactive media. However, there are several problems with the experiment and especially with such an interpretation. First of all, the experiment is a laboratory experiment that provides an artificial set-up that cannot be applied generally to all teaching. The students in the experiment were not trained to use interactive media in teaching, and the teaching itself was not based on written interaction. The teacher had not planned questions designed for the specific teaching activity, and there was no shared virtual arena for teachers and students.

In communicative terms, the students were perceived separately; they could not help each other, or discuss the film through the digital media. To this, the didactically misunderstood use of media did not stop here. What the students wrote digitally they were not allowed to use to answer the tests they were exposed to afterwards, they were only allowed to use hand-written notes. In other words, the teaching was not organised to improve teaching through the use of digital media, why the students did not benefit from their online activity. The media were used to distract the students not to help them learn individually or collectively. However, those with a slightly relevant digital writing activity later remembered and understood more from the film than those with the totally irrelevant online activity.

The researchers could just as well have asked the students in groups 5 and 6 to read Donald Duck while viewing the film and then conclude that printed texts distract and affect learning badly. Groups 7 and 8 could just as well have been asked to write irrelevant things on paper. Groups 1 and 2 could just as well have been asked to read a text in a paper book about a topic related to the film while watching it. Groups 3 and 4 could just as well have been asked to write relevant things on paper that they were not allowed to use in the test. The meaning of the experiment must have been to distract the students, forcing them to multitask, switching to more or less irrelevant and not synchronized topics. 
Furthermore, the article does not sufficiently emphasise the fact that groups 1 and 2 performed almost as well as the control group. It is not hard to imagine that these two groups would have been able to do even better than the control group if minor changes had been made. The students did not collaborate through written interaction while seeing the film. Had this been allowed (and the students had been trained in this area), their understanding of the film would probably have improved and they would probably have performed better. Likewise, if they had been allowed to use the written interaction as shared notes that they could use during the test on equal terms with handwritten individual notes, they would probably have done even better. And last but not least, during the film groups 1 and 2 were bombarded with predefined questions which were related to the topic of the film but not synchronised with it. If the teacher had participated in the written online interaction alongside the students, and had synchronised questions and comments with the film as well as the students' collective interpretation process, this would have helped the students. In other words, if the teacher had acted as a teacher and had taken advantage of the opportunities offered by the new medium environment for collaboration, interaction, note writing and interpretation, a more favourable situation would have been created. Overall the didactics of the experiment was not transformed to match the possibilities of the new medium environment.

\section{Part II: Towards a new understanding of social media, written interaction and education - from multitasking to multiplexing}

In the sections above, we have put forward two main arguments: firstly, that multitasking should not be conflated with multiplexing. And secondly, that there are shortcomings in the conclusions proposed by Kuznekoff et al. implying the false prejudice that use of social media and written interaction can only result in educationally damaging multitasking. However, Kuznekoff et al. do not separate multitasking carefully from multiplexing, why beneficial possibilities are overlooked and/or rejected without proper justification. In the following we want to show how teachers can develop different kinds of teaching involving the use of social media and written interaction through multiplexing to benefit learning and education. We start by describing this in general terms, presenting our theory of three waves. We then present an empirical study demonstrating the potential of multiplexing more precisely, as well as the consequences.

\section{The digital medium revolution and the theory of the three wavesii}

The theory of the three waves describes the general patterns of how schools respond to the new conditions digital media create compared to the media situation before the internet. We propose that these responses involve a shift from closed classroom teaching to an open community between students, teachers and third parties. However, this shift does not happen in a single phase. Rather, we suggest that it arises through three waves containing different educational responses to the new situation. In the theory, we assume that before digital media there was a given level of educationally relevant attention. This assumption can be called into question insofar as the attention devoted to educationally relevant subject matter differed from student to student, class to class, time to time, etc. However, there is no doubt that what we can generally observe is a drop in educationally relevant attention in the first wave of digital media and wireless networks (Mathiasen et al. 2014). We also know that activity irrelevant to educational purposes (e.g. responding to private messages) significantly harms grades, the recollection of information and note taking (Kuznekoff et al. 2016). 
In our research from 2006-2018, we observed that the first response by teachers and schools to the new media situation is either to ignore the new difficulties and possibilities or to prohibit the self-initiated use of digital media for both educationally relevant and irrelevant purposes (Tække \& Paulsen, 2013). Both strategies - ignoring and prohibiting - generally fail for several reasons (ibid.). At the same time, new possibilities for teaching are not actualised or invented. In the first wave, we consistently observe not new and improved teaching, but destabilised teaching with students trying to multitask and switching between computer games or social media and educational interaction with teachers, who do not know what to do.

The second wave arises when schools, teachers and students begin to make use of the possibilities of the new media to improve the interaction between students and teachers. In this phase, teachers begin to use the new media to draw attention back to the classroom by using digitally based written interaction within the class and shared online documents in which students collaborate (monitored and guided by teachers). The result is an intensified educational interaction, attracting increased attention and improving the potential for participation. For instance, it becomes possible for teachers to get answers from all the students simultaneously through the use of written interaction in a medium like Twitter, instead of only hearing one voice at a time. This is just one way to get more students involved and engaged in the educational interaction (Tække \& Paulsen, 2013). In addition, educational quality can be increased with the use of digital media, which also opens for new and more developed forms of organisation (ibid.).

Despite the positive impact of the second wave, it only consists of 'more' and 'better' interaction and does not alter the classroom setting and the educational form radically. But the third wave - which is truly radical - is made possible by the digital literacy and Bildung developed and facilitated during the second wave.

The third wave arises when people other than students and teachers use the internet to become integral parts of educational interaction. When this happens on a regular basis, it changes the educational form that has existed more or less since the acquisition of the printing press. Instead of a closed system of interaction between teachers and students, we now have an open system of interaction in which other people outside the classroom participate and contribute. This brings new perspectives to the form of education. On a regular basis, students meet people with other perspectives, views and responses, and the teacher becomes a 'mediator of otherness'. In this wave, the teacher supports networks for educational purposes outside the classroom. Students connect to groups, other school classes, individuals and databases, using the new medium environment as part of their education. They take part in the convergence culture (Jenkins, 2008) by carrying out produsage (Bruns, 2008), learning to navigate and take part in the new society and its forms of production, network, communication and culture. The upshot is that teaching shifts from being an activity in a closed classroom to being an open activity, inviting different people to participate. Instead of transmitting knowledge to the students, the role of the teacher involves connecting students with relevant others and making knowledge production possible across borders and differences.

In the first phase, teachers and schools have to find middle ways between extreme versions of prohibiting and ignoring. This leads to the second phase: the use of digital media for educational purposes and what we call the 'intensified classroom'. This does not completely solve or repeal the distractions of the first wave, but it does deal with them more adequately. Furthermore, the digital skills, experiences and competences achieved during the second phase enable and motivate the class to enter the third and final wave, where other people are contacted with the aim of contributing to the educational process. These alterations are both more practical and fundamental than shifts in learning theory. What we propose is not only a model of shifting learning theories, and not only a theory of distance learning pedagogy, but rather a general educational theory of how the practice of education as such changes in the era of digital media, also accounting for the non-digital elements of education. 
As part of our research leading up to the theory of the three waves, we conducted a three-year action research project called the Socio Media Education (SME) experiment from 2011 to 2014 (Tække and Paulsen, 2013). The empirical findings in this project enable us to go into greater detail and outline more concretely not only each of the three waves, but also the difficulties of moving from phase one to phase two and from phase two to phase three. In the project, we followed an upper-secondary school class and tried to provide the teachers and students with some good media habits and a higher level of reflectivity in relation to media use and attention (Tække and Paulsen, 2013; 2016). In the SME project we also conducted interviews, observations, self-reports and tweets from the teachers and students during the entire three-year period (ibid.).

\title{
The Socio Media Education project and multiplexing
}

Based on observations, interviews and Twitter posts from the three-year action research experiment called the Socio Media Education project (SME), following a class throughout the three years of their upper-secondary education in Denmark, we can conclude that the potential improvements presented above can actually be achieved (Tække \& Paulsen, 2016; 2017). One important element of the SME project was that the class and its teachers had to use Twitter for written interaction in all classes. This meant that the students became skilled Twitter users. One example of the activities involved was that the students had to tweet about the films they were watching while they were watching them.

\author{
Student 1: When we saw a film, the teacher questioned us on Twitter and we had to \\ answer. I think it was really good. \\ Researcher: And why was it good? \\ Student 1: Because then you got it if it was something essential... something that you \\ did not get. \\ Student 2: ... instead of remembering it all after the film. It can be relatively difficult to \\ remember a whole film afterwards. \\ Researcher: Wasn't it difficult? \\ Student 1: No, not really, you only lose a few seconds because it is running at the \\ same time. What you lose is just how the picture was.
}

Student interview from Tække \& Paulsen (2017)

As shown in this interview, the parallel written interaction supports the educational attention and understanding in the process, as well as the production of notes that the students can draw on later. The fact that the student has to relate actively to the teacher's and other students' questions triggers reflections and focus. At the same time, the students can ask questions if they cannot keep up with the plot. In addition to this the students did not spend time on other activities on digital media while they were tweeting about the film they were watching. According to the teacher, the subsequent analytical discussion (after the film-viewing and tweeting session) was better than the norm in other classes. The point is presumably that the students' film reception was framed analytically while they were watching the film because they were not only watching the film but also tweeting about what was going on in it.

Consequently, even the academically weakest students seemed to gain some analytical understanding of the film. This case shows the strengths of multiplexing. The students have only one intentional object (the plot of the film), but the horizon in which they understand and interpret the plot is enriched by input from the teacher and the other students. 214 tweets were sent during the film, with the teacher drawing the attention of the students to important aspects in writing. The students answered questions from the teacher and other students, as well as making comments and engaging in meta-communication about the reception of the film. The Twitter log shows that the written interaction is not linear, but that there is a clear nonlinear coherence of meaning. For instance, a question might be answered three lines later with other comments, answers and questions coming in between. Compared with oral interaction, no problems were observed because there was no linear turn taking. It is easy to skim down the Twitter 
feed and construct the coherence. At the time of this session the class had only been practising with Twitter for a little more than a month. They were able to understand and use hashtags, so they could exclude all other Twitter interactions going on at the same time, but they did not yet master the use of tags. As a result, they used the name of the student or teacher with whom they wanted to communicate, or just posted a tweet hoping (due to the nonlinear meaning coherence) that the others would understand the link and trusting others to understand the communicative context of their tweet. Not all students were equally good at writing on Twitter, ${ }^{1}$ but they did all have the benefit of the written interaction both while watching the film understanding it and afterwards using it as notes. These students normally do not have the capacity to even write notes for themselves and would not have any notes after the film if it were not for the written interaction. The multiplex strategy provided this group with support both while watching the film and afterwards. According to our observations, there were no other screen activities other than the film watching and the Twitter second-screen activity. This could indicate that the educational use of the screen reduces the level of external distraction. Later observations showed that if the teacher did not sit next to the students, some students were tempted to start other screen activities as well. In addition, when the use of Twitter become a routine part of everyday life, the students' fascination with it declined and distraction became a bigger risk. However, when we compare this class with other classes, or with an early episode in the SME class when a teacher did not ask the students to use Twitter and showed them a film, none of the students paid full attention to the film. Some did homework for other classes, six of them played a car game with each other, some looked at adverts for clothes, and some were on Facebook (Tække \& Paulsen, 2013). This means that a multiplex strategy as described above may reduce irrelevant distractions, but only if the teacher decides how everyone should use social media and perhaps sits next to them and participates in the activity as well. The strongest finding is that the multiplex activity in itself leads to an improvement in the teaching compared with the previous form of teaching, in which everyone wrote their own notes by hand. Multiplex activity enriches the learning environment, extending the meaning horizon and making it social, including input from all the students who can manage to write while watching. We have documented similar effects in relation to oral presentations and other teaching activities (see Tække \& Paulsen, 2013). Interviews with teachers revealed that other classes at the school did not manage as well as the SME class, presumably because they were not trained to use Twitter for school work. As we shall see in the next section, thanks to its Twitter training the SME class gained competences and Bildung, enabling them to contact networks in the outside world after the first year.

From the second year onwards, the teachers in the SME class had to work on cultivating contact between the class and the outside world to establish dialogue with network resources. By multiplexing the class should achieve that the otherwise disturbing contact with the outside world would become an educational asset and hereby turn the situation for the better so the contact, instead of drawing attention away from the educational interaction, would qualify it. Moreover, our thesis was that this contact would enrich and inspire the information situation with angles and perspectives extending beyond what the teacher could offer. In general, this process would teach the class to work in a modus adequate to the contemporary media environment. iii One example was when the literature teacher initiated contact with the Danish poet Kasper Anthoni. The class read one of his collections of poems and spent two sessions asking him questions on Twitter. According to the teacher, the students usually have little or no interest in poetry, but this contact really got them interested. The students also said that the experience was highly motivating and indeed even mind-blowing.

\footnotetext{
${ }^{1}$ It may be a matter of training how good a person can become performing multiplexing, but as with other skills we do not have the same opportunities for development.
} 


\begin{abstract}
Student 1: I think it was a totally different way to analyse poems. A much better way I
\end{abstract} think.

Student 2: Yes, when we have the author [on Twitter] we can question him if there is something we can't understand in the poem and ask him what he meant and then he can send us a tweet about it.

Group interview 1, 31/10 2012

Student 1: It helps with the interpretation. If I ask him how he got the idea, then he says that he had a feeling, and then it is easier to interpret the poem. I think it was good.

Group interview 5, 31/10 2012

The teacher fades slightly into the background, but still takes the responsibility, letting the students go to the source and letting the source be the centre of their attention and reflection. The teacher contacted the poet and set up the arrangement, and helped the students to read the book by designing good questions for the poet and dividing the students into groups for the sessions. This was a good investment, because the students' motivation and involvement were triggered by the direct contact with a real poet through Twitter. The multiplex activity, with the students working with the poems, interacting with the poet on Twitter, discussing (orally) whether they understood the answers they got and what to ask next, taking quotations from the book and trying to get the poet to elaborate etc. all kept the students concentrated. The teacher circulated constantly around the groups of students to support them. This case again shows the strengths of multiplexing and demonstrates that it can be performed as a singletask learning situation. The students had only one intentional object (the poem under discussion), but the horizon in which they understood and interpreted the poem is enriched not only by the teacher and other students, but also by the poet himself. Compared with the second wave case (the film), this third wave multiplex strategy seems to reduce the level of irrelevant distractions even more. Our interpretation is that this has to do with the real and authentic cases involved in the third wave. Such setups with real people in real situations apply to new normal expectations and interpellate the students in the academic work and educational interaction. This means that third wave multiplex teaching not only seems to be more efficient in terms of student learning processes, but also seems to reduce the level of distraction and make the students more motivated and engaged.

Multiplexing with Twitter in parallel with teaching activities also meant that some of the students began to use Twitter to contact other people outside the school. One example of this was that a student used Twitter to contact her sister (a student of economics in Copenhagen):

Student 2: We had to do a presentation about the American presidential election and then the presenter said something I didn't - and we had to use Twitter during the presentation, so I wrote to my sister on Twitter about it. Then she answered, and I could catch up and understand the presentation again.

Group interview 6, autumn 2012

After the presentation, the student explained the difficult part of the presentation to the rest of the class. Once again, this is evidence of the way in which multiplexing can lead to new and useful knowledge being gained from outside the classroom.

Another third wave example in which Twitter was used as a second screen involved some of the students and teachers from the class sitting (by arrangement) at home one evening watching a TV documentary about the financial crisis, and using Twitter to interact about it. After some time, one of the students observed that the rest of the Danes watching the documentary while on Twitter were using a global hashtag to interact about it. 


\begin{abstract}
Researcher: So you were discussing the documentary with the others from the class and
\end{abstract} then it was extended. What do you think of that?

Student: You also got other people's opinion [...] and there were really a lot of opinions and tweets and it went on long after the programme ended. It was really exciting.

Researcher: Was it good for the discussion that it was not just the class and your teachers?

Student: Yes, I believe so. Because we may have many of the same opinions in the class, because we have the same teacher, and we all do the same things. And then there were other people's opinions, people that are another place in their lives and have another perspective on society.

Student interview 9, 9/1-2013

The educational interaction is enriched, and perspectives are gained from the outside. The typical situation in the echo chamber, where the teacher decides what is good and what is bad, right and wrong, fades away. As we saw with the poet, the cultivated opening pushes the position of the teacher who must find a new position. Not necessarily weakened, but more adequate with the new media environment as a "mediator of otherness" that helps the students understand the different opinions in society. We asked the student what it would be like if the SME class had not had the contact to the outside world:

\begin{abstract}
Student: Yes then I believe, then it would be biased, the teacher's opinion would shine through very much. Now we get others' opinions, others' view on things. This means that what the teacher says is not just right, but that you can also find information about: can this really be true? Why does she say that? And such things. So it makes us think in another way.
\end{abstract}

Student interview 9, 9/1-2013

In the third wave, we see that the students are more involved and motivated in relation to their school work. An old book written by an old man describing an old outdated case simply does not appeal to most students in Danish upper-secondary schools. During the work with third wave methods, students form networks and are trained to do so and also trained to handle social codes on the web. This means that during their education, they actually learn something about the outside world for which the school has to prepare them. One of the key roles of schools involves preparing students for the world of today and not for the world of yesterday. This does not mean that they do not need to know anything about Ancient Greece or Rome or world literary history. It only means that the teacher must find setups that feed into the way young people can be attracted and motivated in the present day. The multiplex activity of watching the documentary at home while discussing it with the teacher and classmates provides a constructive second screen activity helping to understand, creating notes and increasing concentration. The opening provided by the global hashtag confronted the students with authentic perspectives from the outside world, triggering both engagement and understanding of the different perspectives existing in society. The closed classroom lacking real world perspectives and only enlightened by the teacher and students is enriched. The risk of fake news and manipulation is reduced by the presence of the teacher and the confrontation of different perspectives and voices. Last but not least, the second screen is not used for multitasking activities but to provide more perspectives and information, better concentration and learning. 


\section{Conclusion}

Multitasking and distraction are problems in the new medium environment, and Kuznekoff et al. (2015) try to pinpoint this fact. But unfortunately, the design of their experiment and their intepretations have left the impression that the medium itself is the problem and not the way it is used. As we have shown, if they are used in an appropriate way, interactive media can also improve teaching. In this article we have rendered it probable that the view taken by researchers like Kuznekoff et al. (2015) is both reductionistic and damaging for the debate about digital media in relation to education. What is properly justified in their article is that they, like others before them, show that we do learn less if we are distracted by digital media providing us with content which has nothing to do with what we are trying to learn. In this article we define this as a multitasking situation in which we try to follow other intentional objects than the one we are trying to learn about, a situation which does not have a constructive influence on our understanding and learning. Moreover, in the article we have defined singletasking as something that includes the constructive situation in which the student, for instance, discusses the intentional object with the teacher and other students. This is where the concept of multiplexing becomes relevant, defined as the situation in which we have our attention on the same intentional object using more than one medium. What we have rendered probable using the theory of the three waves and the examples from the SME experiment is that the use of social media for written interaction makes it possible to multiplex in a wide range of different educational situations in educationally beneficially ways. The student can engage in written interaction looking for answers or relevant questions or comments regarding the educational object. This is the emergence of an educational interaction system based on writing. The system enriches student reflections and learning by granting access to the knowledge and perspectives of the whole class and its teachers, and in the third wave also from people from the outside world as well. Because the interaction is written, it can be used as notes afterwards. Because the interaction is mediated digitally, it does not demand that all the participants are physically present. All in all, this renders it probable that digital media, not least social media, can be used with good educational results and do not necessarily lead to multitasking per se. Digital media enrich the medium environment, providing us with several new possibilities for communication, participation, organisation, categorisation, retrieving etc., thereby providing a scaffold for learning.

\section{References}

Aagaard, J. (2018). Teknologier i klasselokalet - en magtfuld fristelse. København: Unge Pædagoger, 2018(2), s. 48-57.

Bardhi, F. J., Rohm, A, \& Sultan, F. (2010). Tuning in and tuning out: media multitasking among young consumers. in Journal of Consumer Behaviour / Consumer Behav. 9. 2010, pp. 316-332.

Bruns, A. (2008). Blogs, Wikipedia, Second Life and Beyond: From Production to Produsage. New York: Peter Lang.

Chou, C., Condron, L. \& Belland, J. C. (2005). A Review of the Research on Internet Addiction. in Educational Psychology Review, Vol. 17, No. 4, December 2005.

Eisenstein, E. (1983). The Printing Revolution in early Modern Europe. Cambridge: Cambridge Uni. Press.

Elf, N., Hanghøj, T., Skaar, H., \& Erixon, P.-O. (2015). Technology in L1: A review of empirical research projects in Scandinavia 1992-2014. Contribution to a special issue Paradoxes and Negotiations in Scandinavian L1 Research in Languages, Literatures and Literacies, edited by Ellen Krogh and Sylvi Penne. L1 - Educational Studies in Languages and Literature, 15, 1-89.

Fahey, C. \& Meaney, T. (2011). Conversation is the New Attention. In State of the Web, Business, April 19, 2011. http://www.alistapart.com/articles/conversation-is-the-new-attention/

Feng, S. F., Schwemmer, M., Gershman S. J., and Cohen, J. D. (2014). Multitasking vs. multiplexing: Toward a normative account of limitations in the simultaneous execution of control-demanding behaviors. In Cogn Affect Behav Neurosci. 2014 March ; 14(1): 129-146. 
Finkelhor, D. (2011). The Internet, Youth Safety and the Problem of "Juvenoia”. Paper from University of New Hampshire, Crimes against Children Research Center. http://www.unh.edu/ccrc/pdf/Juvenoia\%20paper.pdf

Greenfield, D. N. (2000). The Net Effect: Internet Addiction and Compulsive Internet Use.http://www.virtualaddiction.com/a neteffect.htm 20.9.2009

Greenfield, D. N.(1999). Lost in cyberspace: the web @ work. http://www.virtualaddiction.com/pdf/lostincyberspace.pdf 20.9.2009

Hougaard, A. (2018). World at Your Phone: How 'Snappers' Embody the Digital World. Rask 47. University Press of Southern Denmark, pp. 109-134.

Jenkins, H., Ford, S. and Green, J. (2013). Spreadable media-Creating value and meaning in a networked culture. New York: New York Uni. Press.

Jenkins, H. (2008). Convergence culture: Where old and new media collide. New York: New York University Press.

Jenkins, H. (2006) Confronting the Challenges of Participatory Culture: Media Education for the 21st Century. London: The MIT Press.

Jørgensen, K. G. (1993). The shortest way between two points is a good idea: Signs, Peirce, and theorematic machines. In The computer as medium. Andersen, Holmqvist, \& Jensen (ED). Cambridge Uni. Press.

Kardaras, N. (2016). It's 'digital heroin': How screens turn kids into psychotic junkies. New York Post 27. August 2016.

Kuznekoff et al. (2015). Mobile Phones in the Classroom. in Communication Education, 64:3, 344-365.

König, C. J. (2005). Working Memory, Fluid Intelligence, and Attention Are Predictors of Multitasking Performance, but Polychronicity and Extraversion Are not. in HUMAN PERFORMANCE, 18(3), pp 243266.

Lee ,J., Lin, L. \& Robertson, T. (2012). The impact of media multitasking on Learning. in Learning, Media and Technology. Vol. 37, No. 1, March 2012, pp. 94- 104.

Mathiasen H., Aaen J., Dalsgaard C. and Thomsen M. B. (2014). Undervisningsorganisering, -former og medier - på langs og tværs af fag og gymnasiale uddannelser. Hovedrapport 2014 4. runde, 2012-2014. Forskningsrapport 2014 Aarhus Universitet, Center for Undervisningsudvikling og Digitale Medier.

Meyrowitz, J. (1986). No Sence of Place: The Impact of Electronic Media on Social Behavior. Oxford Uni. Press. USA.

O’Brien, J. (2011). UCSF Study on Multitasking Reveals Switching Glitch in Aging Brain. www.ucsf.edu

Ong, W. J. (1982). Orality \& Literacy. Reprinted 2000. New York: Routledge.

Pashler, H. (1994). Dual-task interference in simple tasks: data and theory. Psychological Bulletin, 16, $220-244$.

Pietersma, H. (2000). Phenomenological epistemology. Oxford: Oxford University Press.

Prehn, A. \& Rashid, I. (2017). Forbyd mobiltelefoner i danske skoler - ellers ødelægger vi børnene. Kronik i Politiken 27. september 2017.

Paulsen, M. \& Tække, J. (2010). Trådløse netværk og sociale normer under forandring. In Norsk Medietidsskrift, Bind 17, Nr. 1, 2010, s. 26-45.

Rekart, J. (2012). Taking on multitasking. in Kappan December 2011/January 2012. V93 N4 pp. 60 - 63.

Tække, J. and Paulsen, M. (2017). Digitalisation of education - the theory of the three waves. In Monograph Series from The Centre for Internet Research; Aarhus, Denmark 2017 (vol. 17).

Tække, J. and Paulsen, M. (2016). Undervisningsfaellesskab og loringsnetvark i det digitale samfund. København: Forlaget Unge Pædagoger.

Tække, J and Paulsen, M. (2013). Sociale medier i gymnasiet - mellem forbud og ligegyldighed. København: Forlaget Unge Pædagoger.

Wood, Eileen et al. (2012). Examining the impact of off-task multi-tasking with technology on real-time classroom learning. in Computers \& Education 58 (2012) pp. 365-374.

Young, K. (1999): Fanget $i$ Nettet. København: INTROITE.

Young, K. (2006): SURFING NOT STUDYING: DEALING WITH INTERNET ADDICTION ON CAMPUS. From the Internet: http://www.netaddiction.com/articles/surfing not studying.pdf 20.9.2009 


\section{Authors}

\section{Jesper Tække}

Associate professor

School of Communication and Culture, Centre for Internet Studies, Aarhus University

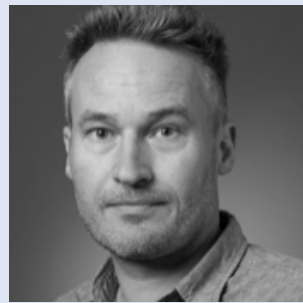

www.jespertaekke.dk, imvjet@cc.au.dk,Twitter:@taekke

\section{Michael Paulsen}

Associate professor

Department for the Study of Culture, University of Southern Denmark

www.michaelpaulsen.dk, mpaulsen@sdu.dk, Twitter: @forskerMP.

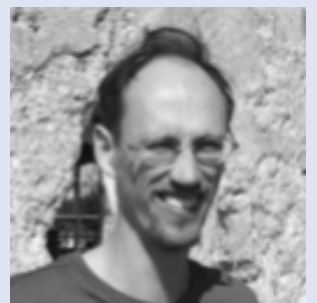

i The concept literally means multi (many) plex (fold), like manifold. Fahey \& Meaney (2011) only mention the concept en passant: "It's not "multitasking" to take notes or have a conversation with your colleagues during a presentation — as long as you're talking about the topic at hand. Some call this "multiplexing," where overlapping tasks are closely related to each other, and even complementary. Attention is not lost in multiplexing - in fact, it is multiplied". The concept is also used in cross fields between neuroscience and computational mathematics in a comparable way with ours (Feng et al. 2014).

ii This section is almost identical to Tække \& Paulsen (2017), and you can read more about the three waves and SME in that article. Later in this paper, we will use some examples from the same article.

iii Following Jenkins $(2013 ; 2008 ; 2006)$, we now see a participation culture characterised by shaping, sharing, reframing, remixing and appropriation, and with Bruns' (2008) produsage and intercreativity. 